\title{
The Role of Technology in Financial Inclusion-A Case Study Mobile Money Penetration in Ghana
}

\author{
Samuel Nii Attoh Abbey \\ Ph.D. in Management, Texila American University Guyana, Ghana
}

\begin{abstract}
With the flagship success of M-Pesa, mobile devices have become an important tool to facilitate the financial inclusion of the previously unbanked population in developing countries. Following the success of M-Pesa in Kenya in 2007, mobile money technologies became widespread across Africa. Beginning in 2009, Ghana experienced exceptional adoption of Mobile Money technology. Many studies have examined the influence of mobile money on financial inclusion from a variety of perspectives, and many have concluded that mobile money is a game-changer in this regard. The Mobile Money concept has evolved based on introducing the other value-added services such as microloans, savings, and insurance portfolios. The researcher used a questionnaire and a face-to-face interview to obtain qualitative data for this study. Together with other research, the statistics revealed that Mobile Money transactions in Ghana had more than tripled since it became the most popular payment method. Over the last year, the platform as a service has created over 140,000 jobs and has shown to be the safest channel. It has several advantages, including lowering the cost of printing and keeping cash on hand, as well as decreasing fraud because the technology underlying it gives appropriate audit trails to prevent fraud and boost economic growth.
\end{abstract}

Keywords: Access to finance, Automated Teller Machine (ATM, Mobile Network Operators (MNO), Cash-lite, developing countries, Development, Ezwich, Fintech, Financial inclusion, Ghana Interbank Payment and Settlement Systems Limited (GHIPS), Mobile phones, Mobile Financial Service (MFS), Mobile Money Interoperability (MMI), Mobile Money (Mobile Money), M-Pesa, Point of Sale (POS), (SME) Small and Medium Enterprises, (SOHO) Small Office Home Office, Telcos.

\section{Introduction}

For the Mobile Money (Mobile Money) industry, the year 2019 was a watershed moment. For an industry that is just a few years old, reaching the billion-dollar mark is a huge accomplishment. In most low-income nations, mobile money is becoming the key to financial inclusion. The purpose of this study is to see how much technology (Mobile Money) has enhanced financial inclusion in Ghana. It is unsurprising that it has also played a significant role in financial inclusion, given its importance in information transmission and financial service provision, particularly the advances related with Mobile Money services. Although there is a substantial amount of research on these themes, the majority of it focuses on the management of mobile technology rather than its costs and advantages. This research would review the literature on mobile technology and its potential impact on financial inclusion in comparison to other payment channels.

It has been suggested that Mobile Money can help the economy by affecting financial and food security, employment, and the accumulation of financial, human, and social capital. It has made it possible for Ghanaians to transfer funds and pay bills like School bills, hospital bills etc.

Mobile Money has arguably become one of Ghana's most secure payment systems, if not the most secure. By supporting innovation for the 
cost-effective delivery of financial products through the use of technology, Mobile Money as a payment service has become the underpinning for financial inclusion. It has aided the impoverished in establishing a stable income and accumulating productive assets. Customers of Mobile Network Operators could use their loyalty to a network to access financial services during lean periods. Services such as overdrafts and microloans can easily be accessed without collateral.

\section{Brief History and Impact of Mobile Money}

M-Pesa was the first mobile money service to enter the African market. As a consequence of a partnership between Safaricom and Vodacom, M-Pesa was launched in Kenya in March 2007. Beginning in October 2005, the system had been used as a testbed for approximately two years before March 2007 [1]. Kenya's subscriber base has risen to 17 million individuals in just four years. It's worth mentioning that Kenya's success rate hasn't been reproduced in neighboring nations like South Africa, Tanzania, Mozambique, and Lesotho, to name a few.

The main goal of the mobile money system was to address the low degree of financial inclusion noticed by experts all over the world in many parts of Africa. According to the [2], there were a few major elements that contributed to M-success Pesa's in Kenya:
1. Safaricom was a key player in the mobile telecommunications sector, having collaborated with Vodafone.

2. In Kenya, sending money by other means was too expensive.

3. After the 2008 election, post-election violence made it even more important to transfer money using techniques that did not need to leave one's home.

4. Depositing funds into a mobile account was safer than depositing funds into a bank account.

5. Mobile money was used to reach hard-toreach places such as slums and rural areas that were unbanked or underserved.

The success of M-Pesa in Kenya has served as an important benchmark for at least the past decade. MTN launched mobile money in Ghana for the first time in 2009, in collaboration with 16 banks [3]. This occurred nine years after Zain (now Airtel) attempted to launch the Zain Zap product in the year 2000. Since MTN's launch in 2009 , mobile money has grown substantially in Ghana, and it is now widely used for making payments, transferring monetary value, acquiring airtime, and, more recently, savings, insurance, and securing micro-loans. The number of mobile money subscribers overtook the number of bank customers in 2014, according to [4], as seen in the diagram below.

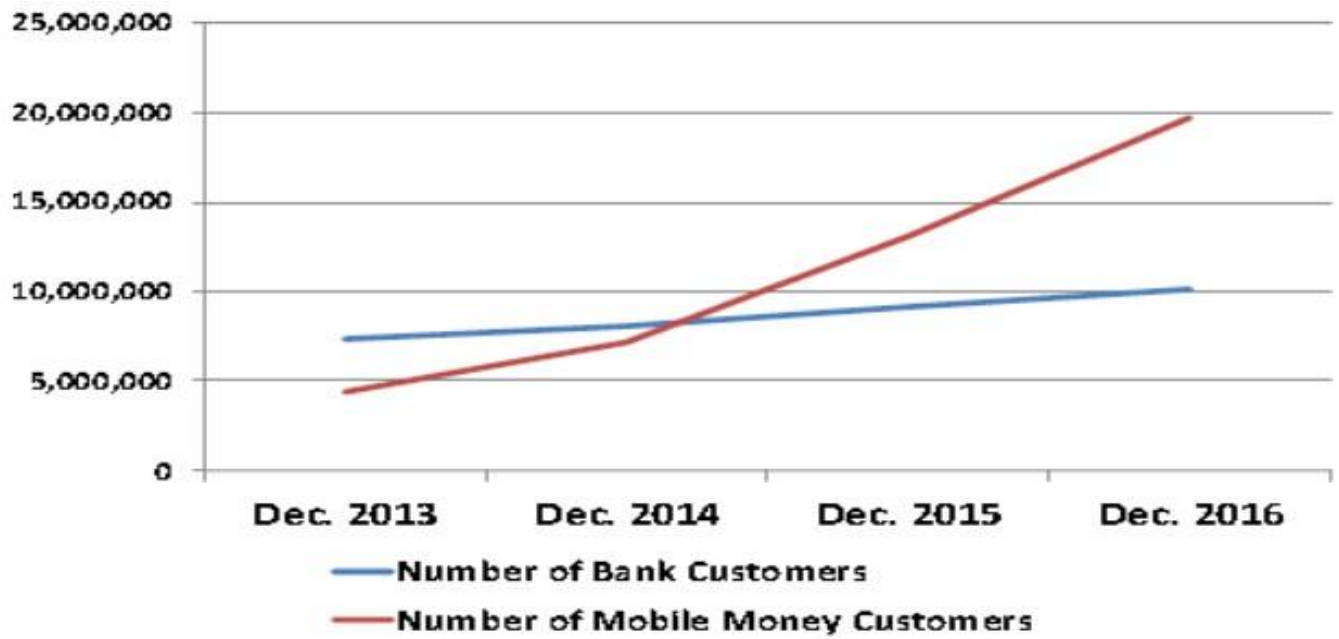

Figure 1. Analysis of Bank Customer vs. Mobile money Customers in Ghana 


\section{Problem Statement}

Since the beginning of electronic commerce, electronic payment systems have evolved gradually. Electronic payment instruments have advanced in popularity around the world, intending to facilitate trade and simplify payment.

There have been various studies on mobile money and its function in financial inclusion; nevertheless, this study aims to determine whether mobile money may better push muchneeded economic growth through digitalization than traditional payment systems, including ebanking, Ezwich, Gh-Link, direct debit and credits, and GHIPS.

\section{Literature Review (Theoretical Framework)}

The provision of inexpensive financial services to the underserved and low-income groups of society has recently been identified as one of the key facilitators of economic development [5]. However, around two billion adults globally lack access to financial services supplied by formal financial institutions [6]. During the 2015 World Bank Group-IMF Spring Meetings, global multi-stakeholders from the public and private sectors pledged to support financial inclusion and set a new global development goal of universal financial access by 2020 [7].

[8] studied the impact of mobile money, particularly M-Pesa, on the economic progress of Kenyan families (since 2008). Because Suri and Jack's study focused on the impact of mobile money as a service, the proximity of mobile money agents to the examined homes (referred to as Agent Density) was a significant part of the study. The findings confirmed that easy access to mobile money led to higher spending levels.

[9] observed that the use of mobile money transactions contributed significantly to sales turnover in Nakuru Town, Kenya, due to the time, cost, and flexibility of mobile money. [10] ascribed mobile money's favorable influence on microbusiness to characteristics such as client convenience, accessibility, cost, and security.

At the national level, an inclusive financial system makes more resources available for investment, particularly in the promotion of small and medium businesses (SMEs).

However, because most impoverished countries lack access to financial services, such financial access benefits are only available to the industrialized world. Financial account provision differs substantially across highincome and developing economies, according to the [11].

The industry was able to directly alleviate some of the financial pressures and personal hardships of the pandemic by delivering social and humanitarian assistance quickly and efficiently, thanks to the unique challenges of the year 2020. By working hand in hand with governments and NGOs, the industry was able to directly alleviate some of the financial pressures and personal hardships of the pandemic. The alliances formed during this trying time are likely to help vulnerable individuals for years, if not decades, to come. Despite the worldwide economic slump, the volume of money moved through mobile money continues to increase. The global value of mobile money transactions has surpassed $\$ 2$ billion per day for the first time and is predicted to cross $\$ 3$ billion per day by the end of 2022 [12].

At the end of 2018, there were over 400 million registered mobile money accounts in Sub-Saharan Africa this number is expected to reach 600 million by 2025. According to [13], Ghana (together with Rwanda and Zambia) had a faster rate of mobile money adoption than Kenya, reaching $100 \%$ in five years vs eight years in Kenya. According to [14], mobile money is responsible for the creation of 400,000 new jobs in Africa. The Ghana Revenue Authority has benefited from the adoption of mobile money since it has increased the visibility and traceability of revenue received in the informal sector, reducing the state's tax deficit [15]. 


\section{Mobile Money Penetration in Ghana}

Mobile Money has improved transaction efficiency and forced changes to the traditional banking system in the country.

Mobile Money technology has disrupted industries such as financial services, agriculture, health, education, energy, transportation, and logistics, to name a few.

The financial services industry is a good example. According to the Bank of Ghana, mobile money transactions totaled more than GHS220 billion in 2018, representing a 169 percent CAGR from 2012. There are currently 13.1 million active mobile money accounts. This figure is larger than the 12 million bank accounts registered in the country, demonstrating that mobile technology is playing an important role in promoting financial inclusion.

As of the third quarter of 2019, Ghana had 16.7 million unique mobile subscribers, 15.1 million smartphone devices, and 10.7 million mobile internet users. As of January 2021, $38.9 \%$ of Ghana's population aged 15 and up have a mobile money account. Users of mobile money increased over the previous three years, but dropped somewhat in 2021, from 39 percent in 2020 to 38 percent. In Ghana, the value of mobile money transactions climbed by more than 30 percent in March 2020.

Ghana is one of Africa's most important mobile money marketplaces. The Mobile Money market in the sub-region is being boosted by factors such as the growing trend of convenience in service delivery, the expansion of the Mobile Money agent network, and the deployment of Mobile Money interoperability. Various regulations and standards have also been created to strengthen and protect the country's Mobile Money system. MTN, Vodafone, and AirtelTigo are the three primary mobile network operators in Ghana. MTN is the top depositor, with more than $90 \%$ of Mobile Money accounts held by the company. With GH79 million, or 3.56 percent of the deposits, AirtelTigo ranks second while Vodafone, with GH57 million in deposits, ranks third with $2.52 \%$ market share.

\section{Market Breakup by Technology}

1. Unstructured Supplementary Service Data (USSD).

2. Mobile Wallets.

In Ghana's mobile money sector, USSD now holds the majority of the market technology.

\section{Market Segmentation based on Business Model}

1. Mobile Led Model.

2. Bank Led Model.

In Ghana's mobile money market, the mobileled approach now has the highest share.

\section{Market Segmentation based on Transaction Type}

1. Peer to Peer (P2P).

2. Peer to Merchant (P2M).

3. Bank to Wallet.

4. Wallet to Bank.

5. Bill Payments.

6. Airtime Top-ups.

The peer-to-peer transaction type currently has the largest market share.

\section{Mobile Money Vs. Banking}

Mobile Money is a financial-regulated payment service that allows anyone with a valid national ID card to open an account at any of Ghana's mobile money agents. Users can deposit (cash-in) and withdraw (cash-out) funds at an agent's stand or ATMs once the service is activated. Mobile users can also transmit money straight from their phones to other mobile money users, as well as from their bank accounts to their mobile wallets. Mobile Money service has accelerated convergence between the telecom sector and the medium of exchange, given the rapid growth of mobile networks and the country's low banking penetration (money). MTN, Ghana's biggest mobile telecom provider, was the first to provide mobile money services in 2009. Other telecommunications networks, such as AirtelTigo and Vodafone, have now entered the mobile money industry, fiercely battling with the market leader. The Ghana cedi 
is almost as widely used as the Mobile Money service today. On the other hand, Banks are not as widely distributed as the money they oversee due to the concentration of financial activity in cities.

There has been substantial advancement in the field since 2009, when the first mobile money client was served. With a total client base of over 35 million, mobile money accounts are used by $17 \%$ of them. According to the Bank of Ghana, the number of persons using mobile money has been rapidly expanding, more than doubling in the last year to $36 \%$. The value of transactions jumped by $483 \%$ from GHC 2.4 billion in 2013 to approximately GHC11.6 billion in 2014

\section{Design and Methodology}

This Chapter discusses the design paradigm, data collection method, study setting, and data analysis method in detail.

\section{Research Design}

A case study-based methodology was used in this research. The choice of this case study was to perform an in-depth analysis of how Mobile Money has impacted the day-to-day financial activities of the research population.

\section{Data Collection}

A questionnaire was created with primarily closed-ended questions to capture the sample size's perspectives on the subject and add greater significance to the research results. Qualitative research frequently uses closed-ended questions because they are easier to model statistically [16]. Incorporating this questionnaire into the study topics in focus was thought to be beneficial by the researcher. The survey gave a broad picture of the impact of mobile money on financial inclusion.

A few business owners were also interviewed to get their thoughts on how Mobile Money has influenced their day-to-day operations. Due to the nature of their work, these business owners are highly busy and were unable to complete the online Google Forms questionnaire; however, they agreed to a face-to-face interview.

[17] believe that combining semi-structured interviews with structured questionnaires is an acceptable method for approaching a research issue. This is because both methods have flaws that can be minimized by combining them. The goal of this mixed approach is to provide conclusive results.

Their study, [18] addressed concerns that mixed methods research could push qualitative analysis to the background. In the study, the researcher has prioritized qualitative analysis when assessing the study's findings.

\section{Research Questions}

1. Do you have a registered and active Mobile Money account?

2. Which Mobile Network Operator(s) is/are your provider(s)?

3. Which Payment mode is much easier to use, Mobile Money or Bank?

4. Are you comfortable with the transaction charges?

5. Are you able to access loans easily via your Mobile Money Account?

6. Are the repayment terms flexible?

7. Is your mobile money wallet connected to your bank account?

8. Which of the transfer options below is easier for your daily transaction?

9. Which of these activities are easier for you to perform?

10. Mobile Money agents are more strategically positioned and easier to access than banks, do you agree?

11. Accessing loans from the bank is much easier. Do you agree to this statement?

12. Do you think that keeping a Mobile Money account is safer?

13. Does the daily transaction limit on Mobile Money impact your activities negatively?

14. If a cashless system was introduced, which of the payment mode below would be your preferred option and why? 


\section{Ethical Assurance}

Ethics in the context of research refers to the "appropriateness of behavior concerning the rights of those who become subject to your work or affected by it" [19] To address these ethical issues, the researcher endeavored to gain initial access by stating the objectives to the respondents, and the fact that it was purely for academic purposes.

\section{Findings and Discussion}

In this chapter, the study's primary findings were discussed. Before discussing the input supplied by the owners of small businesses interviewed during the research, the data acquired through a questionnaire was evaluated first. It will serve as the foundation for the last chapter.

\section{Demographics of the Data}

Using an online form to collect pertinent data for this study proved to be more successful. The researcher was able to gather a total of eightyfive (85) replies to the questionnaire. The following are some of the responses: $98.8 \%$ confirmed they have a registered and active Mobile Money account, while $1.2 \%$ responded that they do not have a Mobile Money account. This question measured whether the respondents were abreast with technology and its role in their daily financial activities (Figure 2).

\section{Do you have a registered and active Mobile Money account?}

84 responses
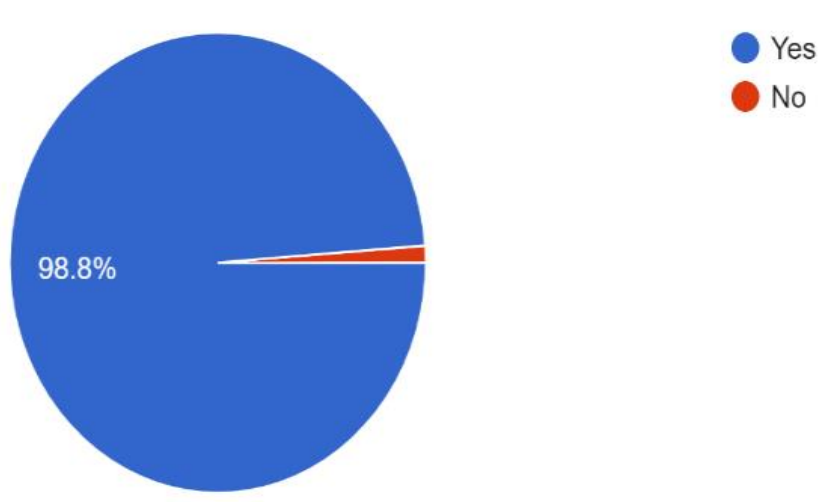

Figure. 2. Mobile Money Account Status for Respondents

The study progressed to assess which Mobile Network Operator holds the largest Mobile Money wallet. $70.2 \%$ of the respondents confirmed that they use MTN. 59.5\% use Vodafone, while Airtel/Tigo had $10.7 \%$ of the respondents. This shows that MTN has maintained its relevance in the Telecom sector by building financial inclusiveness using technology (Figure 3). These respondents confirmed that they have registered and active
Mobile Money accounts because of the ease it provides. The researcher further assessed which payment mode is much easier. This is comparing the traditional banking method (Electronic Banking) versus Mobile Money. 96.4\% of the respondents confirmed that transactions done via Mobile Money are much easier than the Banking channels. $3.6 \%$ also of the respondents believe that the Banking channel is much easier (Figure $4)$. 


\section{Which Mobile Network Operator(s) is/are your provider(s)? \\ 84 responses}

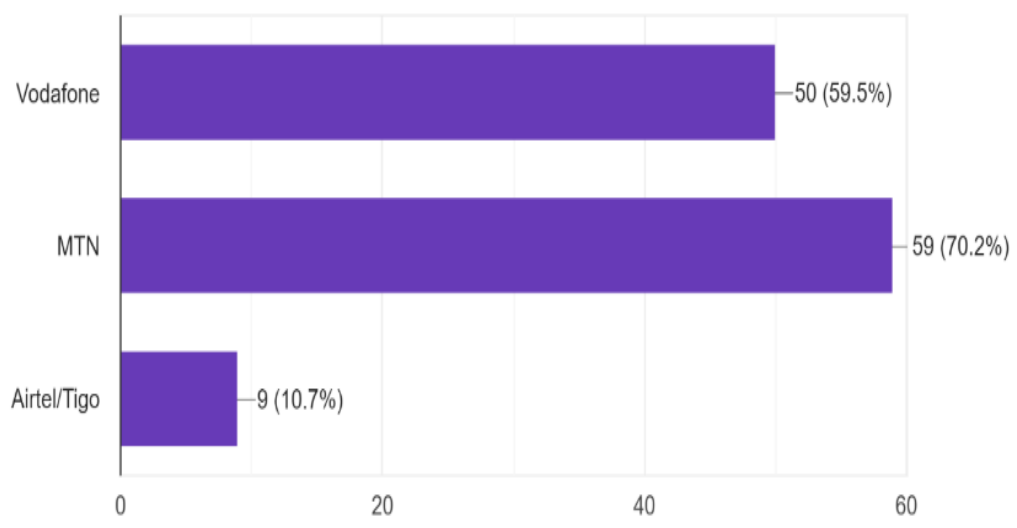

Figure. 3. Summary of Mobile Money Subscriptions per MNO

\section{Is it easier to use MoMo in your daily transactions than Bank payment method? \\ 83 responses}

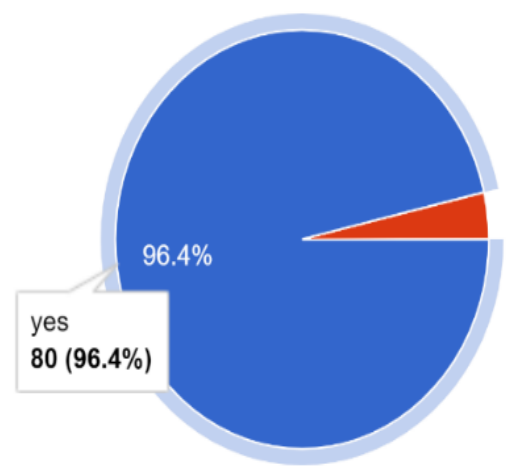

Figure 4. Mobile Money vs. Bank Payment Method

The researcher also assessed if the transaction charges pose too much burden on the respondents. Although Vodafone has scrapped all transfer charges, even across networks, the impact is low since a majority of the Mobile Money users are registered on the MTN network where transfer charges are still being applied. These charges are stratified ranging, from $1 \%$ to $1.5 \%$ based on the amount transferred. Twentythree (23) respondents translating to $33.3 \%$ of the survey population, felt that transfer charges were far lower compared to the bank charges, which are between Ghs3- Ghs5 p/t. Three (3) respondents translating to $4.2 \%$, stated that their provider (Vodafone) does not apply transfer charges. Two (2) respondents, which form $2.9 \%$ of the people surveyed, were indifferent about the charges. Some of the verbatim from the respondents stated that the charges were too high and must be reduced. $59.6 \%$ of the respondents who felt that the charges were too high suggested that the charges must either be reduced or there should be a cap on an amount that could be transferred without attracting charges. Figure 5 below shows the statistics of the responses to the transaction charges. 


\section{MoMo Transaction Charge}

Mobile money's ability to contribute to financial inclusion and socioeconomic improvements has also improved as the business model has evolved.

The category of respondents to the survey was mainly people of the working class and between the ages of 31 years to 50 years. The researcher sought to know whether or not these respondents have an appetite for microloans. The researcher compared how easy it was to access loans via Mobile Money to Banks. Figures 6 to 9 have the age demographics of the respondents, and a confirmation that accessing loans via Mobile Money was easier with flexible payment terms.

$40 \%$ of the respondents confirmed it is much easier to access loans via Mobile Money, 22.5\% said it is difficult accessing loans via Mobile Money, while $37.5 \%$ have never accessed loans via Mobile Money. $65.4 \%$ of the respondents said the repayment terms for loans accessed via Mobile Money were flexible, whereas $34.6 \%$ felt the repayment terms were not flexible. The Mobile Network Operators charge between 5\% to $6 \%$ interest per month on these microloans.

The researcher further inquired to know whether accessing loans through the banks is much easier than accessing microloans via Mobile Money. $67.6 \%$ of the respondents disagreed with the statement. $20.3 \%$ strongly disagreed, while $12.2 \%$ agreed that accessing loans through the banks is a lot easier than the Mobile Money Channel.

Please select the age range you belong

13 responses

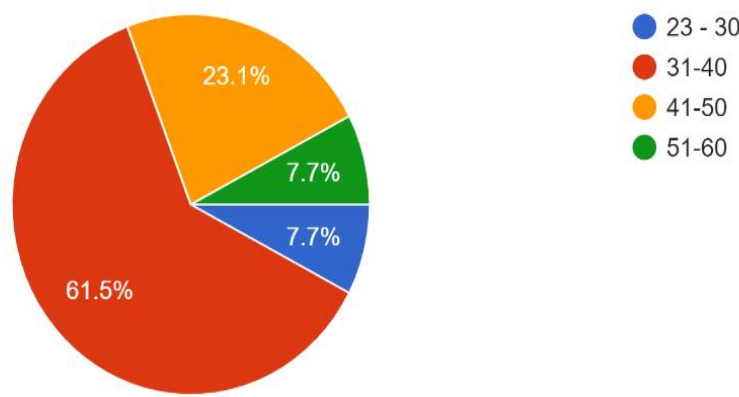

Figure 5. Age Demographics for Respondents

Are you able to access loans easily via your Mobile Money Account?

80 responses

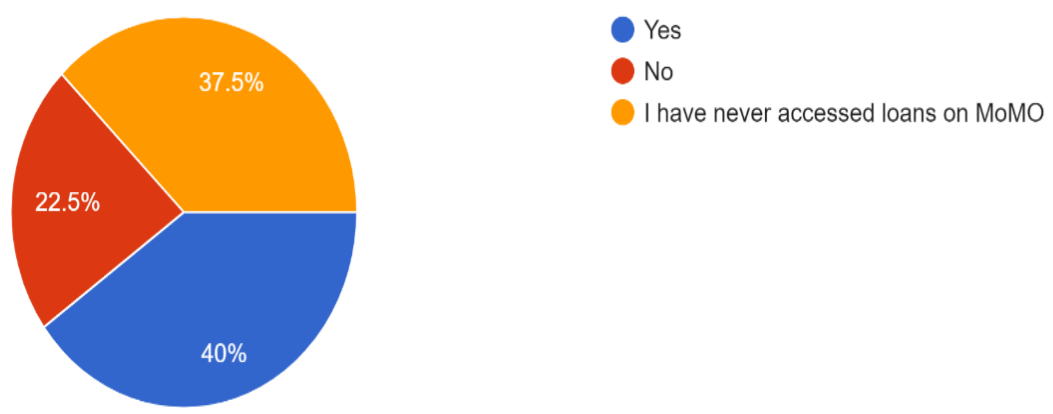

Figure 6. Summary Responses on Loans Accessed 
Are the repayment terms flexible?

52 responses

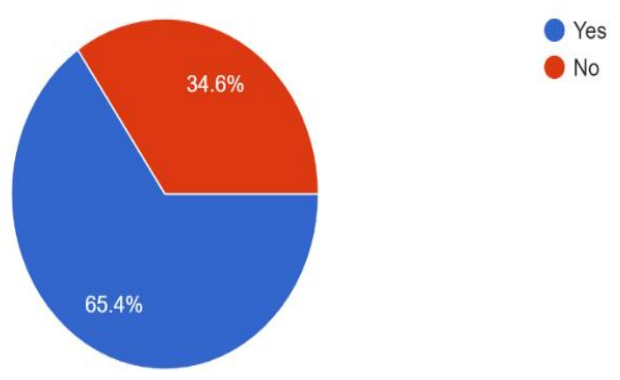

Figure 7. Response on the Flexibility of Loans Repayment via Mobile Money

Accessing loans from the bank is much easier. Do you agree to this statement

74 responses

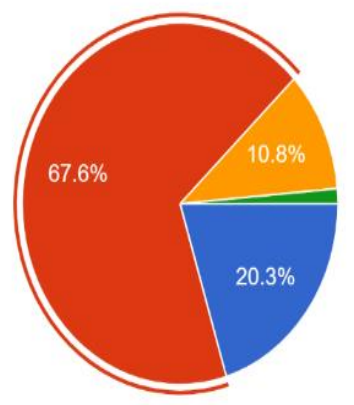

Strongly disagree

Disagree

Agree

Strongly agree

Figure 8. Summary of the Ease of Loan Access via Banks

The study also analyzed interoperability with regards to how easily the respondents can transfer funds without moving from their location. This aspect is measuring the ease of money circulation and the channel which facilitates it. The survey also sought to know how many respondents had integrated their
Mobile Money accounts into their Bank accounts and whether the daily Mobile Money transaction limits provide any setbacks. $72 \%$ of the respondents confirmed that their Mobile Money account is integrated into their bank accounts, while $28 \%$ said "No".

Is your mobile money wallet connected to your bank account?

82 responses

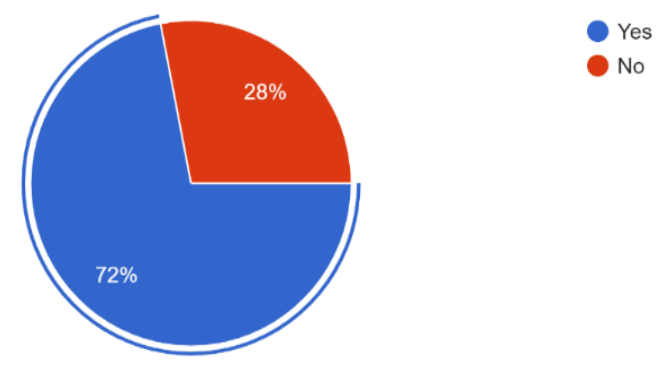

Figure 9. Summary of Respondents Mobile Money Wallet Integration into Bank Account 
We further measured bilateral transactions, and $93.1 \%$ of the respondents confirmed that Bank-to-Wallet transaction is more convenient to perform. $29.2 \%$ also felt that wallet-to-Bank transaction is more convenient. However, this is impacted by the transaction limit or tier of the subscriber. The banks usually allow up to 10,000 Cedis transfers to the Mobile Money wallet daily, whereas a person with a lower-tier on Mobile Money can perform up to 5,000 Cedis transfers from the wallet to the bank daily.

\section{Which of the transfer options below is easier for your daily transaction? \\ 72 responses}

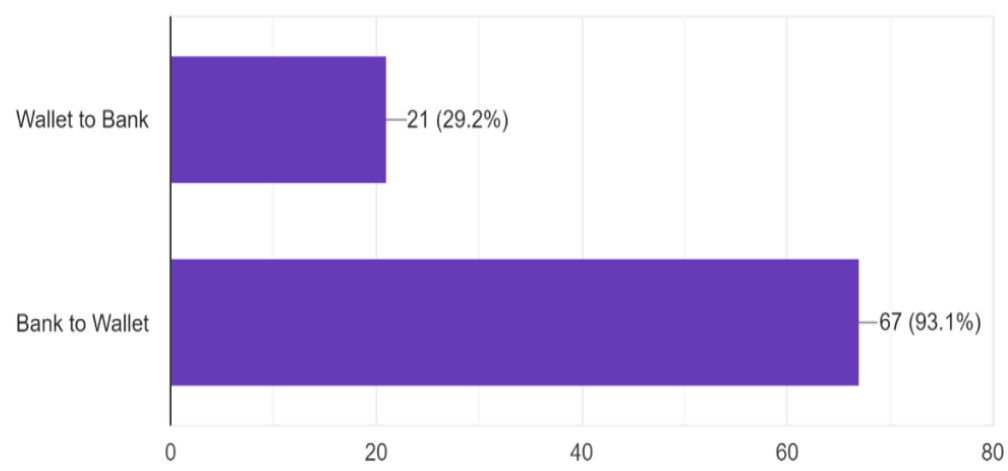

Figure 10. Summary Responses on Wallet Transfers

$58.3 \%$ of the respondents confirmed that the transaction limits do not have any negative impact on their daily activities. $21.4 \%$ responded that the limit sometimes affects their daily transactions. Some of the verbatims are in the chart below:

\section{Does the daily transaction limit on Mobile Money impact your activities negatively? \\ 84 responses}
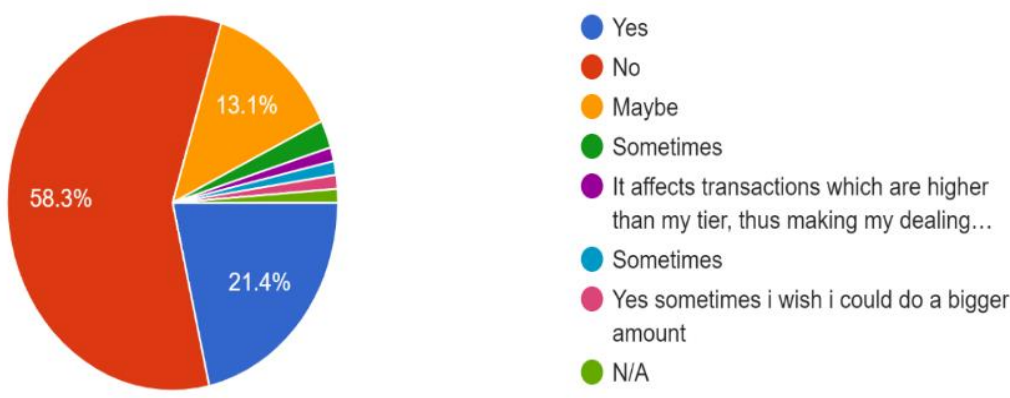

Figure 11. Impact of Mobile Money daily transaction limits

The research further assessed the relevance of mobile money agents within the value chain. Mobile money agents provide a convenient and trustworthy way to change cash to a digital value and vice versa, which is critical for account uptake and extending financial inclusion. They also serve as the public face of mobile money services, performing important responsibilities such as onboarding. As of the first half of 2019, there were over one hundred and eighty thousand $(180,000)$ active mobile money agents in Ghana, around four percent more than in the same period of 2018. In the study, we requested feedback on the proximity to agents compared 
felt that it was not safe to keep a Mobile Money Account. They provided a verbatim that banks are safer compared to the several recorded incidents of Mobile Money Fraud. 32.9\% were indifferent and provided feedback such as (quite safe, somehow, and maybe).

Finally, the respondents were asked to choose their preferred payment channel in a situation where a cashless system is introduced in the country. They had an option to choose multiple answers from the list provided. $80.7 \%$ responded that their preferred channel would be Mobile Money. 5\% selected a combination of Mobile Money and electronic banking, stating the international money transfer limitation on Mobile Money. 20.8\% chose electronic banking. $4.8 \%$ preferred cheques.
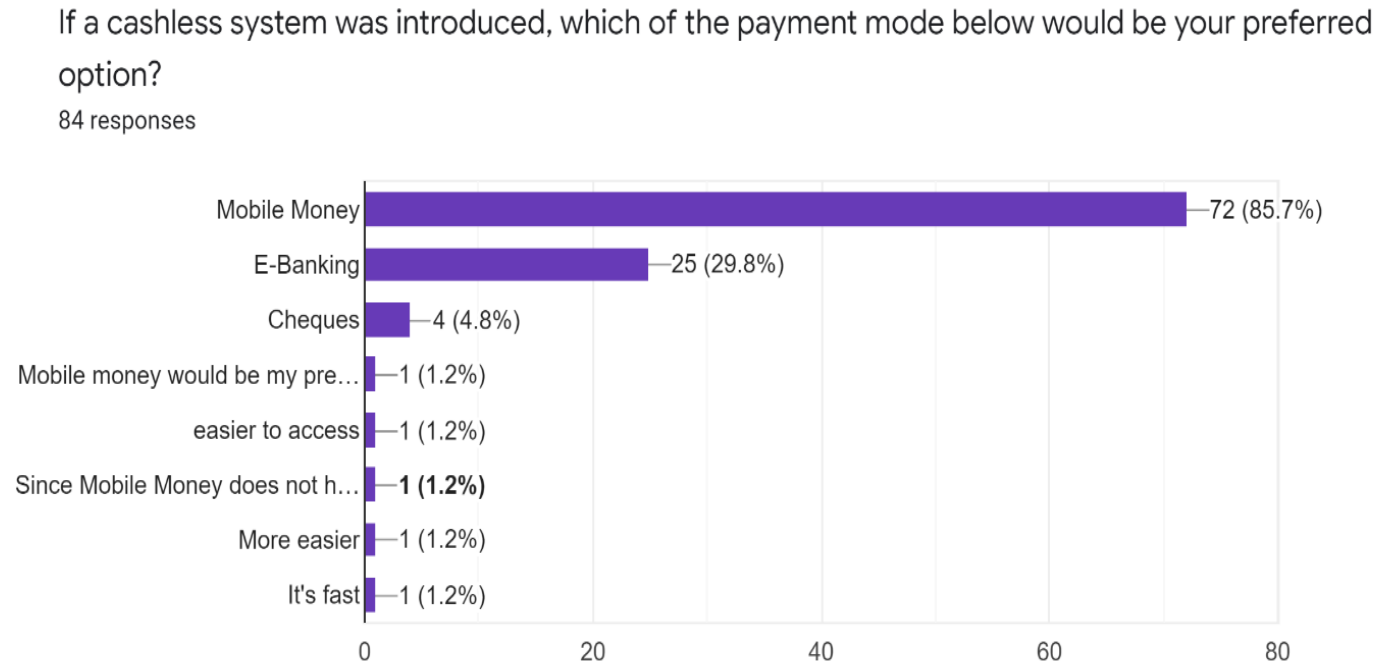

Figure 14. Responses on Preferred Payment Mode for a Cashless System

Per the responses provided by the sample size in this study that the most preferred payment method is Mobile Money because of the convenience and comparatively safer way of transacting business. It confirms the research by [20] that Mobile Money as a service has by far contributed to economic growth more than any other payment channel.

They described this discovery to several factors, including:

1. Ease of moving cash across people with different spending patterns.

2. Increased remittances.

3 . Higher savings returns.

4. Increased credit availability and risksharing.

The researcher also interviewed people whose businesses can be classified under SME and $\mathrm{SOHO}$, to explore the role Mobile Money has played in their businesses. The face-to-face interviews that were done during the investigation proved to be extremely informative to the researcher. The interview gave business owners a chance to talk about their experiences with mobile money. When it came to interviewing questions, they were designed to answer the questions posed at the outset of the study and expose the researcher to fresh experiences and points of view that could be beneficial in future research. The line of business for the five business owners who were interviewed are Mother-care shops, eateries, and groceries. Below are narratives on the interviews. 
Table 1. Interview responses from Business owners about their perception on Mobile money

\begin{tabular}{|c|c|c|c|}
\hline Name of Business & Nature of Business & Business Start Date & A Narration of the interview responses \\
\hline \multirow[t]{3}{*}{ Ben-Ans Mother care } & \multirow{3}{*}{$\begin{array}{l}\text { Dealer in children's } \\
\text { clothing, baby food and } \\
\text { other essentials for } \\
\text { kids. }\end{array}$} & \multirow[t]{3}{*}{$12 / 01 / 17$} & $\begin{array}{l}\text { Business Owner started using mobile money based on customers' requests for a more flexible } \\
\text { payment process. }\end{array}$ \\
\hline & & & $\begin{array}{l}\text { She was also happy about the free MMI introduced by her provider (Vodafone). This action she } \\
\text { described as big savings to her business }\end{array}$ \\
\hline & & & $\begin{array}{l}\text { She also emphasized time management and security provided going cashless. It has saved him } \\
\text { from moving to banks to deposit money into the account of her suppliers and possible robbery } \\
\text { which has been the nightmare of most shop owners. However, she had one unpleasant experience } \\
\text { where a fraudster used a pseudo-process to zap her MoMo account. But her provider assisted to } \\
\text { block the fraudster's account and help her to retrieve her money through an official police report. }\end{array}$ \\
\hline \multirow[t]{3}{*}{ DeNods Eateries } & \multirow[t]{3}{*}{$\begin{array}{l}\text { Providers of fast foods } \\
\text { and Local dishes }\end{array}$} & \multirow[t]{3}{*}{$30 / 07 / 2019$} & $\begin{array}{l}\text { The business owner confirmed that logistics involved in transporting cash to the bank have been } \\
\text { eliminated following the adoption of mobile money. }\end{array}$ \\
\hline & & & $\begin{array}{l}\text { She can pick orders online and used dispatch for delivery. Payments have been facilitated by the } \\
\text { Mobile Money services. This has also promoted safety during the Pandemic. }\end{array}$ \\
\hline & & & $\begin{array}{l}\text { When asked whether mobile money business has boosted her business. She confirmed that the } \\
\text { service has played a significant role in keeping her business going. She's able to access the micro } \\
\text { loans during very critical terms and repayment terms are much flexible. }\end{array}$ \\
\hline KiddyTrix Mothercare & $\begin{array}{l}\text { Dealers in children's } \\
\text { clothing, learning } \\
\text { materials and all } \\
\text { essentials for kids and } \\
\text { breastfeeding mothers }\end{array}$ & $20 / 03 / 2017$ & $\begin{array}{l}\text { When the business owner was asked to share her thought about the introduction of cashless } \\
\text { system and her preferred payment mode, she mentioned that she is already operating a cashless } \\
\text { system. As a former banker, she realized the importance of using a cashless process as a means to } \\
\text { eliminating fraud or embezzlement on the part of her staff. She said about } 90 \% \text { of her customers } \\
\text { use MoMo. } 8 \% \text { use debit cards and } 2 \% \text { use cheques. }\end{array}$ \\
\hline \multirow[t]{3}{*}{ CreamyBakes } & \multirow[t]{3}{*}{ Pastries and eateries } & & $\begin{array}{l}\text { The Business owner responded that her bakery depends heavily on mobile money for } \\
\text { transactions and salary payments. }\end{array}$ \\
\hline & & & $\begin{array}{l}\text { She does not see any significant impact of mobile money on business growth; however, she } \\
\text { found the easy access to microloans as a good initiative. }\end{array}$ \\
\hline & & & She advised step-ups to start using mobile money since it provides the needed security. \\
\hline \multirow[t]{2}{*}{ The Grocers } & \multirow[t]{2}{*}{$\begin{array}{l}\text { Dealers in groceries } \\
\text { and fresh foods. }\end{array}$} & \multirow[t]{2}{*}{ April 1, 2011} & $\begin{array}{l}\text { The Manager agreed with the value of mobile money as a technology that has introduced } \\
\text { convenience and reduced the risk of theft to payments. }\end{array}$ \\
\hline & & & $\begin{array}{l}\text { He considers mobile money more reliable compared to banking hall of ATMs given the very low } \\
\text { occurrences of system outages in mobile network systems. He also considered proximity to the } \\
\text { banks and the ATMs as a challenge. }\end{array}$ \\
\hline
\end{tabular}




\section{Conclusion and Recommendations}

A variety of favorable conditions, persistent investment, operational competence, and a commitment to innovate and digitize an expanding payment ecosystem have all contributed to mobile money's amazing success. Mobile money originated as an innovative private solution that allowed consumers to transfer and receive money with other customers of the same service, similar to other payment infrastructures. Mobile money was once a standalone tool in many nations, not tied to a centralized third-party platform and largely distinct from other forms of digital money.

In Ghana, the technology behind Mobile Money has progressed by integrating into several channels such as POS, merchant services, and banks. The industry is becoming more integrated with international financial providers, in addition to domestic interoperability and interfaces with banks. This initiative addresses one of the key limitations uncovered as part of the findings of this study. Another benefit that the Mobile Money service has offered businesses is the option to pay salaries through the platform. Employees have can subscribe to receive up to $30 \%$ of their salaries via the Mobile Money platform, which is usually paid in the middle of the month. This option cushions families to address financial incidentals which may occur during the month.

The introduction of Microloans is another great innovation driving the use of the Mobile Money service. This facility has been of great benefit to most households, and though it has no direct impact on business growth for those operating under SME/ SOHO, start-up businesses can benefit from the portfolio. Another area of concern which the MNOs need to tighten is platform security. Given several incidents of Mobile Money fraud, the respondents raised this as a concern and part of their reasons for preferring to stick to the banks than using Mobile Money. Suffice to say that MTN has taken a proactive step to introduce the use of valid national identity cards for cash-out transactions via agents. This process will help easily trace all doubtful withdrawals. It will be prudent for the remaining MNOs to adopt the same strategy to build customer trust.

There is no doubt that Mobile Money is now bigger than all payment platforms. According to [21], the mobile money payment platform has a transactional value of 89.1 billion Ghana Cedis. This represents a $96.6 \%$ increase from the same period last year. In comparison, all other payment channels combined - direct debits and credits, checks, Gh-link, Ezwich, and Ghipss Instant Pay (GIP) - recorded a total transaction value of 26.3 billion Ghana Cedis, accounting for roughly a third of the value recorded for mobile money platforms. Cheque payments totaled 17.9 billion Ghana Cedis in transaction value, direct debit 105.4 million Ghana Cedis, direct credits 5.1 billion Ghana Cedis, and Ezwich 710.7 million Ghana Cedis. Gh-link set a new high of 33.1 million Ghana Cedis, while GHIPPS topped 2.5 billion Ghana Cedis.

This essentially indicates that Mobile Money services continue to be the preferred and most convenient payment platform because they are accessible to all mobile phone users. Local enterprise and innovation will undoubtedly be boosted by the financial and technological ecosystems (mobile money platform). The active subscriber base has grown from 15.5 million to 18.3 million as of June 2021. Over the last year, the Mobile Money platform has created jobs for over 140,000 new agents, bringing the total number of active agents from 23,000 to 403,000.

Despite the significant role of Mobile Money, there are a substantial number of transactions that are still being performed using hard currency. This explains why the introduction of a cashless system would require a collaboration between the Banks and the Telecommunication Companies to make this a reality. Such cooperative initiatives will encourage better economies of scale through infrastructure resource pooling, lowering capital expenditure, and speeding up the digitization of the value 
chain for merchants and users. Access to financial services is a foundation for success, yet many obstacles continue to obstruct efforts to reach the underserved. The future, on the other hand, promises to provide fresh prospects. In combination with Smartphones, the "payments as a platform" paradigm, will empower the majority of young entrepreneurs and small enterprises by providing access to new skills and revenue-generating options. Taking advantage of these potential, as well as overcoming barriers like digital literacy and achieving economies of scale to reach the last mile, will necessitate a collaborative effort across the mobile money ecosystem. The most powerful factor for digital financial inclusion and broadening the reach of mobile money will continue to be keeping the demands of the underserved at the center of stakeholder dialogue.

Finally, the co-integrating link between the volume of mobile money transactions and the value of mobile money transactions implies that growing financial inclusion and progress toward

\section{Reference}

[1] The Economist. (2015). Why does Kenya lead the world in mobile money? [online] Available at: https://www.economist.com/the-economistexplains/2015/03/02/why-does-kenya-lead-theworld-in-mobile-money.

[2] The Economist. (2015). Why does Kenya lead the world in mobile money? [online] Available at: https://www.economist.com/the-economistexplains/2015/03/02/why-does-kenya-lead-theworld-in-mobile-money.

[3] Kenneth Chidi Igiri, Arden University, 2020. Impact of Mobile Money on SMEs in Ghana Since 2018 Final. [online] Available at: https://www.researchgate.net/publication/339677715 _Impact_of_Mobile_Money_on_SMEs_in_Ghana_S ince_2018_Final [Accessed 29 Aug. 2021].

[4] Bank of Ghana. Payment systems. Department. August 2017 impact of mobile money on the payment system in Ghana: An Econometric Analysis. [online]. Available at: https://www.bog.gov.gh/wp- a cash-lite economy have a long-term relationship. This means that variables that encourage the use of mobile money help to promote financial inclusion and the transition to a cash-lite or cashless economy.

\section{Conflict Of Interest}

I, Samuel Nii Attoh Abbey, hereby declare that except for references to other author's work which have been duly cited and recognized, this Article is the result of my own work. It has neither in part nor in whole been submitted nor exhibited in any Institution for any academic purposes.

\section{Acknowledgement}

I wish to express my sincere gratitude to those who supported me in this Article, especially my respondents. My sincere thanks also go to my dear wife, Mrs. Mildred Nana Takyiwa Abbey for her knowledge, guidance, and support.

Finally, I thank God Almighty for His grace and mercy throughout this work.

content/uploads/2019/08/Impact-of-Mobile-Moneyon-the-Payment-Systems-in-Ghana.pdf.

[5] Ozyurt, S. (n.d.). 2021, Ghana is now the fastestgrowing mobile money market in Africa. [online] Quartz. Available at: https://qz.com/africa/1662059/ghana-is-africasfastest-growing-mobile- [Accessed 29 Aug. 2021]. [6] Geoffrey Muzigiti, 2013. Financial Inclusion is poor in Sub-Saharan Africa. https: www.dandc.eu.

[7] The World Bank, 2018. UFA2020 Overview: Universal Financial Access by 2020. https://www.worldbank.org/en/topic/financialinclusi on/brief/achieving-universal-financial-access-by2020.

[8] Suri, T. and Jack, W. (2016). The long-run poverty and gender impacts of mobile money. Science, 354(6317), pp.1288-1292.

[9] R. Kirui, S. O. Onyuma, 2015. Role of Mobile Money Transactions on Revenue of Microbusiness in Kenya. European Journal of Business and Management. 
[10] Mbogo 2010, as reported in Kirui and Onyuma, 2015. Role of Mobile Money Transactions on Revenue of Microbusiness in Kenya. https://www.academia.edu/20878656/Role_of_Mobi le_Money_Transactions_on_Revenue_of_Microbusi ness_in_Kenya.

[11]The World Bank Annual Report 2012. https://openknowledge.worldbank.org/handle/10986/ 11844

[12] Simon K. Andersson-Manjang Nika Naghavi, 2021. State of the Industry Report on Mobile Money. (n.d.). [online]. Available at: https://www.gsma.com/mobilefordevelopment/wpcontent/uploads/2021/03/GSMA_State-of-theIndustry-Report-on-Mobile-Money-2021_Fullreport.pdf.

[13] GSMA Head Office, United Kingdom, 2019. The Mobile Economy Sub-Saharan Africa. (n.d.). [online]. Available at:

https://data.gsmaintelligence.com/api-

web/v2/research-file-

download?id=45121567\&file=2794-160719-ME-

SSA.pdf.

[14] MTN, 2019. Financial reporting, Annual results https://www.mtn.com/investors/financial-

reporting/annual-results/.

[15]Ecofin Agency, 2018. Orange Partners with NSIA to Deploy Services in West Africa https://www.findevgateway.org/news/orangepartners-nsia-deploy-services-west-africa.
[16] Kwik Surveys, 2018. Create surveys, analyze results, adapt kwikly https://kwiksurveys.com/.

[17] Harris, L.R \& Brown, G.T.L (2010). Mixing Interview and Questionnaire Methods: Practical Problems in Aligning Data. Practical Assessment, Research \& Evaluation 15(1). (n.d.).

[18] JW Creswell, R Shope, VL Plano Clark, 2006. How interpretive qualitative research extends mixed methods research. https://scholar.google.com/scholar?q=Creswell+et+a 1.,+2006)+addressed+concerns+that+mixed+method $\mathrm{s}+$ research+could+push+qualitative+analysis+to+the +background\&hl=en\&as_sdt=0\&as_vis=1\&oi=scho lart.

[19] Mark NK Saunders, 2000. Research Methods for Business

Studies https://www.researchgate.net/publication/201382148 _Research_Methods_for_Business_Studies.

[20] Suri, T. and Jack, W. (2016). The long-run poverty and gender impacts of mobile money. Science, 354(6317), pp.1288-1292.

[21] Economic and Financial Report published in July 2021. 